1985 for the two sets was 1.096 , as compared to 1.091 for the unselected offspring (Table 1), a significant difference $(\mathrm{t}=5.74$, df $=210$ ).

The mean specific gravity of the selected offspring in 1987 was 1.092, as compared to 1.087 for the unselected offspring (Table, $1)$, again a significant difference $(t=7.94$, df = 207)

In both cycles of selection for tuber characteristics, the mean specific gravity of the selected clones was significantly higher by 0.005 than that of the unselected clones. This difference indicates that selection for physical tuber characteristics in this population did not adversely affect specific gravity. In fact, at least in this early stage of the breeding program, such selection led to higher specific gravity in the selected population than the unselected population. However, as indicated by the range of mean specific gravity values, there were undoubtedly several clones in the unselected population that had a specific gravity higher than some of the selected clones. Since the determination of specific gravity for individual clones can be prohibitively time-consuming as larger populations are tested, we are encouraged to note that selection can be made on visual observations in the field without negative impact on specific gravity.

\section{Literature Cited}

Haynes, F.L. 1972. The use of cultivated diploid Solarium species in potato breeding, p. 100110. In: E.R. French (cd.). Prospects for the potato in the developing world. Intl. Potato Center Symp. 1972. Lima, Peru.

Mendoza, H.A. and F. L. Haynes. 1974. Genetic relationship among potato cultivars grown in the United States. HortScience 9:328-330.

Murphy, H.J. and M.J. Goven. 1959. Factors affecting the specific gravity of the white potato in Maine. Maine Agr. Expt. Sta. Bul. 583.

Snedecor, G.W. and W.G. Cochran. 1967. The comparison of two samples. Statistical methods, 6th ed. Iowa State Univ. Press, Ames. p. 91-119.

\title{
Promotion of in Vitro Leaf Growth of Inner Scales Excised from Dormant Onion Bulbs
}

\author{
Kil Sun Yoo ${ }^{1}$, Leonard M. Pike ${ }^{2}$, a-rid B. Greg, Cobb ${ }^{3}$ \\ Department of Horticultural Sciences, Texas A\&M University, College \\ Station, TX 77843 \\ Additional index words. Allium cepa, dormancy, sprouting, growth regulators
}

\begin{abstract}
Inner scales excised from dormant bulbs of the short-day 'Texas Grano 1015Y' onion (Allium cepa L.) were cultured in vitro and leaf growth was examined. Light promoted leaf growth, but no differences in leaf growth were observed for media $\mathrm{pH}$ between 4 and 7 . Leaf growth rate in darkness was highest at $24 \mathrm{C}$, reduced at $15 \mathrm{C}$, and greatly reduced at SC. Kinetin promoted leaf growth at 1,10 , and $100 \mu \mathrm{M}$. IAA was effective at 1 and $10 \mu \mathrm{M}$, but not at 0.1 and $100 \mu \mathrm{M}$. $\mathrm{GA}_{3}$ promoted growth at $0.1 \mu \mathrm{M}$. No inhibitory effects of $\mathrm{ABA}$ on leaf growth could be detected. Chemical

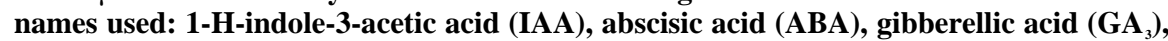
6-furfurylaminopurine (Kinetin).
\end{abstract}

Dormant onion bulbs are almost impervious to external stimuli, and the length of dormancy is affected by cultivar and conditions under which bulbs are grown and stored (Thompson et al., 1972). Onions stored at 10 to $15 \mathrm{C}$ tend to sprout earlier than those stored at higher or lower temperatures (Thompson et al., 1972). Auxin, gibberellic acid (GA), and cytokinin levels have been found to be low and inhibitors high in dormant bulbs. The growth promoter vs. inhibitor condition reverses itself when leaf growth is initiated (Aung and Peterson, 1974; Isenberg et al., 1974; Thomas, 1969). Attempts to break dormancy artificially in whole bulbs by applying $\mathrm{GA}_{3}, \mathrm{GA}_{477}$, 1-naphthaleneacetic acid (NAA), and $\mathrm{N}^{6}$-benzyl-

Received for publication 1 June 1988. The cost of publishing this paper was defrayed in part by the payment of page charges. Under postal regulations, this paper therefore must be hereby marked advertisement solely to indicate this fact.

'Graduate Student.

${ }^{2}$ Professor.

${ }^{3}$ Assistant Professor. adenine (BA) have been unsuccessful (Kate, 1965; Thomas, 1969). However, bulbs with the outer scales removed sprouted earlier (Kate, 1965), and excised inner scales will sprout when cultured in nutrient agar or sand (Jaffe and Isenberg, 1968; Mahotiere et al., 1976a, 1976b).

Our study was conducted to determine effects of medium $\mathrm{pH}$, light, temperature, and plant growth regulators on leaf growth of inner scales excised from dormant onions and cultured in vitro.

Preparation of explants. Three layers of the innermost scales, with the basal plate attached, were carefully removed from medium-size (5.0 to $8.8 \mathrm{~cm}$ in diameter) bulbs of 'Texas Grano 1015Y', a short-day onion. The initial size of the explant was $\approx 3 \mathrm{~cm}$ high and $1 \mathrm{~cm}$ in diameter. For growth measurements, the length of the second outer leaf of the explant was considered to be zero when the scales were excised. Experiments were carried out using bulbs within 1 month of harvest (25 Apr. 1986). Bulbs were stored at $24 \mathrm{C}$ until used. The tissue was surfacesterilized with $70 \%$ ethanol for 1 rein, $10 \%$
Table 1. Effect of medium $\mathrm{pH}$ and light vs. dark culture conditions on leaf growth of excised inner scales from dormant onions after 21 days in vitro culture.

\begin{tabular}{lcccr}
\hline \hline & \multicolumn{4}{c}{ Leaf length $(\mathrm{cm})^{2}$} \\
\cline { 2 - 5 } & \multicolumn{4}{c}{ Medium $\mathrm{pH}$} \\
\cline { 2 - 5 } Illumination & 4 & 5 & 6 & 7 \\
\hline Yes & 5.6 & 6.4 & 8.1 & 5.9 \\
No & 8.6 & 6.1 & 9.0 & 8.8 \\
Significance & \multicolumn{4}{c}{ NS } \\
$\quad$ pH & \multicolumn{4}{c}{} \\
$\quad$ Illumination & \multicolumn{4}{|c}{} \\
\hline
\end{tabular}

${ }^{{ }^{2}}$ Means of nine cultures of inner scales. Initial leaf length was considered to be $\mathrm{O} \mathrm{cm}$.

, $*$ Nonsignificant or Significant at $P=0.0 .5$, re spectively, according to $\mathrm{F}$ test.

Table 2. Effect of plant growth regulator concentration on leaf growth on excised inner scales from dormant onions after 14 days in culture.

\begin{tabular}{ccccc}
\hline \hline & \multicolumn{4}{c}{ Leaf length $(\mathrm{cm})^{z}$} \\
\cline { 2 - 5 } $\begin{array}{c}\text { Concn } \\
(\mu \mathrm{M})\end{array}$ & \multicolumn{4}{c}{ Growth regulators } \\
\cline { 2 - 5 } & Kinetin & IAA & GA $_{3}$ & $\mathrm{ABA}$ \\
\hline 0 & 1.8 & 1.8 & 1.8 & 1.8 \\
0.1 & 3.5 & 4.3 & 4.9 & 4.0 \\
1 & 7.6 & 7.9 & 3.4 & 4.5 \\
10 & 9.5 & 7.6 & 3.6 & 3.0 \\
100 & 12.1 & 5.7 & 3.9 & 1.6 \\
Significance & $* *$ & $*$ & $*$ & $*$ \\
\hline
\end{tabular}

'Means of nine cultures of inner scales. Initial leaf length was considered to be $\mathrm{O} \mathrm{cm}$.

*** Significant at $P=0.05$ or 0.01 , respectively, according to $\mathrm{F}$ test.

commercial bleach $(5.2 \%$ sodium hypochlorite) solution for 2 rein, and then rinsed with sterile distilled water for $5 \mathrm{~min}$. The basal end of the explants were placed $1 \mathrm{~cm}$ deep in medium. Nine explants were used for each treatment.

Preparation of media and culture conditions. To examine the effect of medium $\mathrm{pH}$ and light, the basal medium consisted of fullstrength Murashige and Skoog (1962) inorganic salts, $30 \mathrm{~g}$ sucrosefliter, and $7 \mathrm{~g}$ agar/ liter. The $\mathrm{pH}$ was adjusted to $4,5,6$, or 7 with $0.1 \mathrm{~N} \mathrm{NaOH}$ or $\mathrm{HCl}$. Eight milliliters of medium were placed in $25 \times 150-\mathrm{mm}$ culture tubes and autoclave at $121 \mathrm{C}$ for 15 


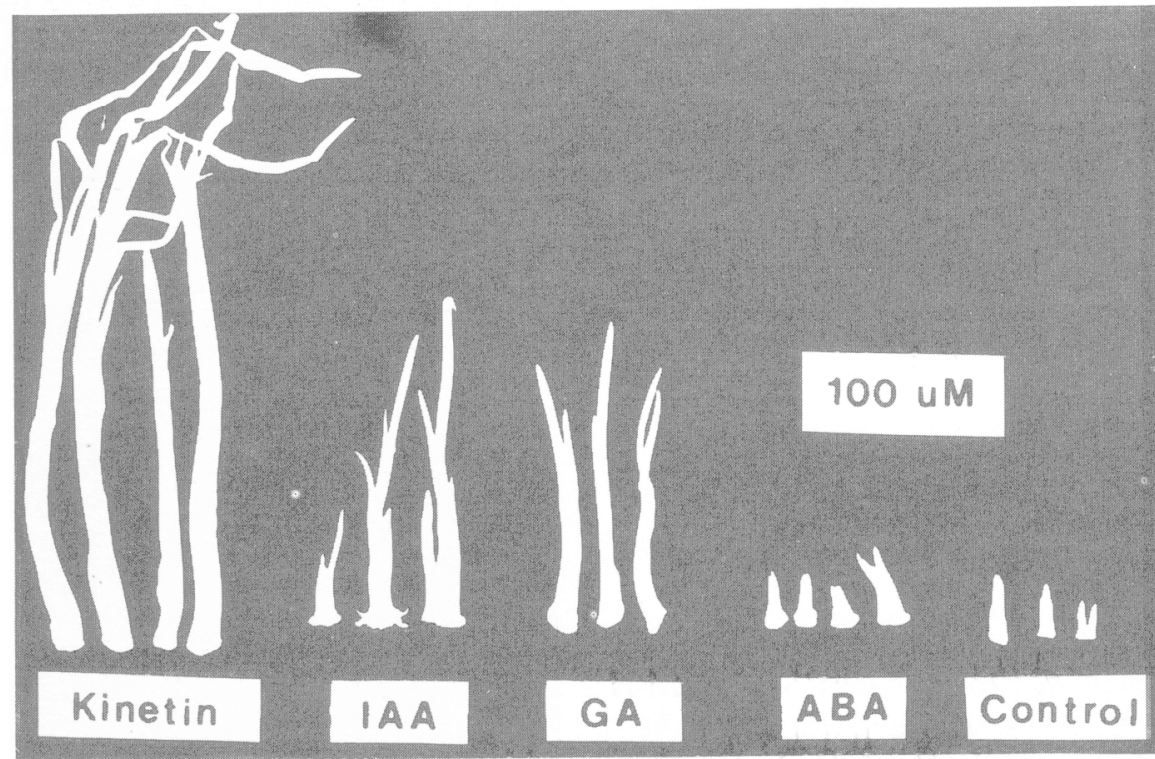

Fig. 1. Effects of $100 \mu \mathrm{M}$ kinetin, IAA, $\mathrm{GA}_{3}$, and $\mathrm{ABA}$ on leaf growth of excised inner scales from dormant onions after 14 days of in vitro culture.

min. Explants were maintained in either darkness or under continuous fluorescent light $\left(15 \mu \mathrm{mol} \cdot \mathrm{s}^{-1} \cdot \mathrm{m}^{-2}\right)$ at $24 \mathrm{C}$. In an initial experiment, leaf growth was observed daily for 21 days, and 2 weeks was selected as the appropriate period to determine treatment effects on leaf growth.

To examine the effect of temperature on leaf growth, explants were kept in incubators at 5,15 , or $24 \mathrm{C}$ in darkness. The same medium described above ( $\mathrm{pH} 5.5)$ was used in this experiment.

The medium examining the effects of plant growth regulators consisted of $\mathrm{ABA}, \mathrm{GA}_{3}$, IAA, or kinetin at $0.1,1,10$, and $100 \mu \mathrm{M}$, respectively, and $0.7 \%$ agar at $\mathrm{pH} 5.5$ (no salts or sugar). The explants were kept in darkness.

Leaf length was measured from the second outer scale after the first outer scale was removed.

Medium $p H$ and light. No differences in leaf growth for media $\mathrm{pH}$ between 4 and 7 were observed in either dark or light culture conditions (Table 1). Although light generally promoted leaf growth, illumination was not required for leaf growth. Roots also grew in light, and root initiation coincided with greening of the leaves. In general, root proliferation was associated with enhanced leaf elongation. Bulbing was not observed in any of the treatments. Other results also indicated that leaf elongation could occur using excised scales (Jaffe and Isenberg, 1968; Mahotiere et al., 1976a, 1976b).

Temperatures and shoot growth. Removal of the outer scales had a dormancy-breaking effect, as previously reported (Jaffe and Is- enberg. 1968: Mahotiere et al., 1976a, 1976b).Leaf growth was greatest at 24C (4.9 $\mathrm{cm})$. Leaf growth response in vitro was different from intact onion bulbs during storage, which showed greater growth at $15 \mathrm{C}$ than at 24C (Thompson et al., 1972). By exposing scales to $10 \mathrm{C}$ before culture, Mahotiere et al. (1976b) noted the promotion of shoot growth in culture at 20C. Since a previous report indicated that sucrose promoted leaf growth (Mahotiere et al., 1976a), sucrose in the medium might have partly promoted leaf growth in the $\mathrm{pH}$ and light or temperature treatments.

Plant growth regulators. Leaf growth was significantly promoted by kinetin at $1 \mu \mathrm{M}$ concentration or higher (Table 2, Fig. 1). growth at 1 and $10 \mu \mathrm{M}$, but not at either lower or higher concentrations. $\mathrm{GA}_{3}$ enhanced growth at $0.1 \mu \mathrm{M}$, but not at the other concentrations and ABA was effective only at $1 \mu \mathrm{M}$. We found no inhibitory effects of ABA on leaf growth.

Root growth was evident in IAA-treated cultures, but not in kinetin-treated explants. Elongated and shrunken outer scales, suggesting a movement of water and nutrients to the growing point, were noticeable in kinetin-treated explants. However, the outer scales remained fresh and did not elongate in the control or ABA-treated explants. Promotion of shoot growth by kinetin in this study seems to support a report of increased cytokinin levels in onion bulbs when leaf growth is initiated (Isenberg et al., 1974). $\mathrm{cm})$, followed by $15 \mathrm{C}(2.6 \mathrm{~cm})$ and $5 \mathrm{C}(0.9$ Leaf growth was positively correlated with kinetin concentration. IAA promoted leaf
$\mathrm{GA}_{3}$ was less effective than kinetin in promoting onion leaf growth in this experiment, although increased GA levels have been observed in sprouting bulbs (Abdel-Rahman and Isenberg, 1974; Aung and Peterson, 1974),

A previous report indicated promotion and inhibition of shoot growth by kinetin and ABA, respectively (Mahotiere et al., 1976a); however, the inhibitory effect of ABA was not evident in our study. Conceivably, the low growth rate of the control prevented detection of inhibition by ABA. The level of $\mathrm{ABA}$ has been shown to be highest immediately after harvest and to be lowest when bulbs sprout (Jaffe and Isenberg, 1968; Thomas, 1969).

Several previous investigators observed that initial leaf elongation up to 2 to $3 \mathrm{~cm}$ occurred, but they did not examine further leaf growth (Jaffe and Isenberg, 1968; Mahotiere et al., 1976a, 1976b). However, we observed actual leaf growth over a longer time interval (4 vs. 14 days) and at different levels of growth regulators than previously reported.

\section{Literature Cited}

Abdel-Rahman, M. and F.M.R. Isenberg. 1974. The role of exogenous plant regulators in the dormancy of onion bulb. J. Agr. Sci. 82:113116.

Aung, L.H. and C.E. Peterson. 1974. Gibberellin-like substances of dormant and non-dormant bulbs of Allium cepa L. J. Amer. Soc. Hort. Sci. 99:279-281.

Isenberg, F. M. R., T.H. Thomas, M. Pendergrass, and M. Abdel-Rahman. 1974. Hormone and histological differences between normal and maleic hydrazide treated onions stored over winter. Acts Hort. 38:95-116.

Jaffe, M.J. and F.M.R. Isenberg. 1968. Rhythmic growth in excised sprout-leaves of onion bulbs. Physiol. Plant. 21:470476.

Kate, K. 1965. Physiological studies on the bulbing and dormancy of onion plant: VII. Effects of some environmental factors and chemicals on the dormant process of bulbs. J. Jpn. Soc. Hort. Sci. 35:49-56.

Mahotiere, S., R.C. Herner, and F.G. Dennis. 1976a. Effect of applied growth substances on growth of shoot apices excised from onions in rest. J. Amer. Soc. Hort. Sci. 101:211-213.

Mahotierc, S., R.C. Herner, and F.G. Dennis 1976b. Effect of temperature on growth of shoot apices excised from onions in rest. HortScience 11:154-155.

Murashige, T. and F. Skoog. 1962. A revised medium for rapid growth and bioassays with tobacco tissue cultures. Physiol. Plant. 115:473497.

Thomas, T.H. 1969. The role of growth substances in the regulation of onion bulb dormancy. J. Expt. Bet. 20:124-137.

Thompson, A. K., R.H. Booth, and F.J. Proctor. 1972. Onion storage in tropics. Trop. Sci. 14:1933. 